\title{
Perancangan Tata Cahaya Buatan dengan Konsep Efisiensi Energi Pencahayaan Kualitatif pada Masjid Baiturrahman, Ciputat, Tangerang Selatan
}

\author{
Rahma Purisari", Muhammad Mashudi \\ Program Studi Arsitektur, Fakultas Teknologi dan Desain, Universitas Pembangunan Jaya, Ciputat, Tangerang \\ Selatan, Banten, Indonesia
}

Submisi: 20 Juni 2019 ; Revisi: 22 Juni 2020; Penerimaan: 28 Juni 2020

\author{
Kata Kunci: \\ Iluminasi masjid \\ Pencahayaan \\ buatan \\ Penghematan \\ energi
}

\begin{abstract}
Abstrak Pengabdian kepada masyarakat yang dilakukan pada Masjid Baiturrahman, Perumahan Villa Bintaro Indah, Jombang, Ciputat, Tangerang Selatan merupakan kegiatan yang bersamaan dengan momentum penting saat masjid sedang melakukan proses perluasan area untuk menambah daya tampung jemaah. Sebagai bagian dari tim renovasi masjid, kami mengambil bagian perancangan tata cahaya buatan untuk memberikan nilai lebih pada masjid serta memberikan pengetahuan kepada masyarakat akan pentingnya penataan cahaya buatan yang efektif dan efisien. Efisiensi energi dan pencahayaan kualitatif merupakan kata kunci dari konsep besar perancangan tata cahaya buatan untuk Masjid Baiturrahman. Dengan focus group discussion (FGD), perancangan pencahayaan buatan, dan sosialisasi kepada warga, pengabdian ini dilakukan agar tata cahaya buatan mampu memberikan rasa aman pada jemaah masjid mulai saat memasuki bangunan hingga memberikan kenyamanan visual saat jemaah melakukan peribadatan. Tidak hanya itu, keindahan arsitektur masjid juga berperan dalam tata cahaya buatan sehingga masyarakat lebih tertarik untuk datang ke masjid. Dengan perancangan hingga penyusunan rencana anggaran biaya yang menjadi luaran yang dihasilkan, tim pengabdi mampu memberikan solusi terhadap kebutuhan desain yang hemat energi, berkualitas, aman dan indah.
\end{abstract}

Abstract The community service conducted at Baiturrahman Mosque, Ciputat, South Tangerang, was a plan carried out simultaneously an important moment where the mosque was undergoing a site expansion to accommodate more people. With the inclusion of the community service team as a part of the mosque's renovation team, we took part in designing the artificial lighting to give more value to the mosque and to give knowledge to people about effective and efficient artificial lighting design. Energy efficiency and qualitative lighting were the keywords of the main concept of the mosque's lighting design. By performing the FGD (Focus Group Discussion) method, designing artificial lighting, and socializing to the mosque member board, this community service aims to provide a sense of security for the mosque community member from the moment they enter the building and to give visual comfort for the worshipers. The beauty of the mosque also took part in artificial lighting arrangements to attract people to come to the mosque. With the design concept up to the budget plan, which was part of the output, the community service team is expecting to give solutions to the design requirements which solves the problems such as energy savings, quality, security and aesthetic.

ISSN 2460-9447 (print), ISSN 2541-5883 (online)

${ }^{*}$ Corresponding author: Rahma Purisari

Program Studi Arsitektur, Fakultas Teknologi dan Desain, Universitas Pembangunan Jaya, Jalan Cendrawasih Raya Blok B7/P, Sawah Baru, Ciputat, Tangerang Selatan, Banten 15413, Indonesia

Email: rahma.purisari@upj.ac.id 


\section{PENDAHULUAN}

\subsection{Analisis situasi}

Perkembangan teknologi informasi yang begitu masif telah mendorong pola pikir masyarakat ke arah yang lebih positif. Peran teknologi menyebarkan informasi terbukti telah memberikan dampak positif terhadap umat Islam dalam memandang sebuah Masjid. Masyarakat makin sadar bahwa memakmurkan masjid merupakan kewajiban bagi orang Islam yang beriman, seperti yang terdapat dalam Al-Quran QS An-Nuur ayat 36, "Sesungguhnya ada sekelompok orang yang bertasbih kepada Allah, menyembahnya di masjidmasjid yang telah diperintahkan Allah untuk dibangun, diagungkan, dan disemarakkan dengan menyebut nama Allah. Mereka selalu berada di situ pagi dan petang."

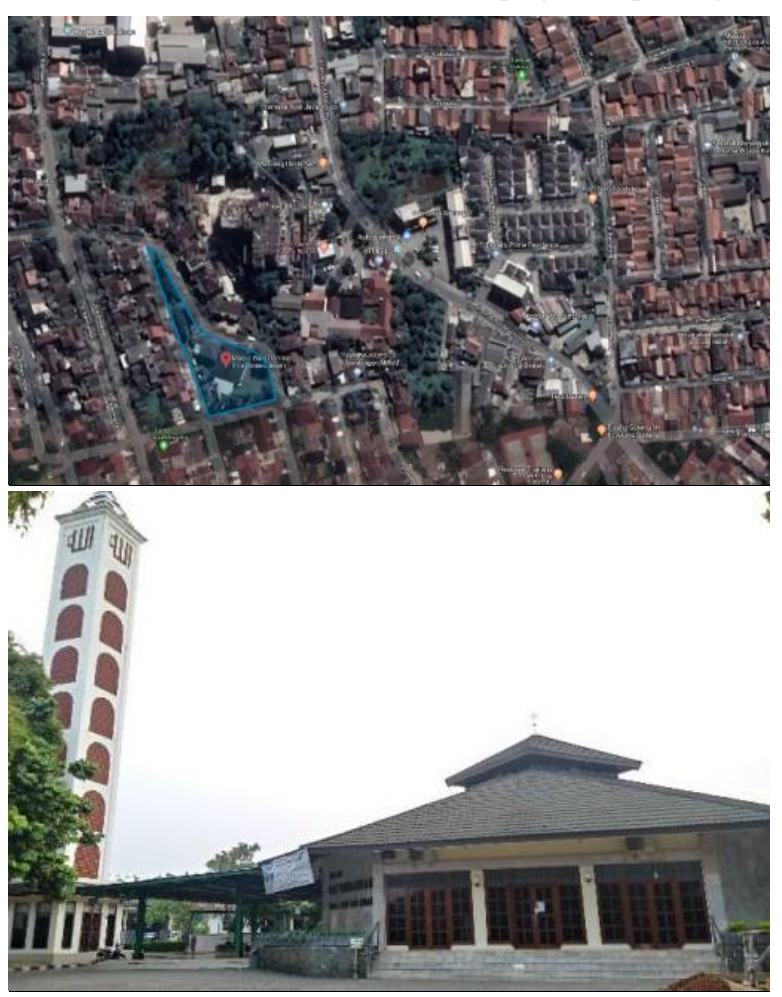

Gambar 1. Lokasi Masjid Baiturrahman

Masjid Baiturrahman didirikan pada tahun 1993 di kompleks Perumahan Villa Bintaro Indah (Gambar 1). Masjid ini pada awalnya dibangun hanya untuk mengakomodasi kegiatan peribadatan warga kompleks perumahan, namun sekarang masjid ini menjadi salah satu dari 10 masjid yang mempunyai jemaah terbanyak di Kelurahan Jombang (Tamimi, 2018). Masjid Baiturrahman direnovasi pada tahun 2011 untuk pertama kali sejak didirikan. Renovasi berupa penambahan sisi kiri masjid untuk tempat salat agar kapasitas naik dari 350 jemaah menjadi 481 jemaah.

Seiring dengan bertambahnya jemaah Masjid Baiturahman, maka pada tahun 2018 dilakukan kembali renovasi agar mampu menampung lebih banyak jemaah (836 jemaah). Yayasan Masjid Baiturrahman merasa perlu untuk mempercepat renovasi ini karena pada saat salat Jum'at, salat Idul Fitri dan salat Idul Adha, masjid sudah tidak mampu menampung jemaah. Peningkatan daya tampung juga dibarengi dengan peningkatan kualitas ruang pendukung seperti ruang wudhu yang lebih higienis, ruang marbot, dan ruang imam masjid yang lebih rapi dan layak. Yayasan Masjid Baiturahman berpendapat bahwa untuk meningkatkan kualitas ibadah, masjid harus ditunjang dengan fasilitas yang nyaman, aman, dan indah.

\subsection{Permasalahan mitra}

Tim pengabdi melakukan penelusuran melalui desktop study sekaligus wawancara tidak langsung dengan ketua yayasan, pengurus dewan kemakmuran masjid (DKM), serta arsitek untuk menemukan beberapa masalah penting dalam rencana renovasi dan perluasan Masjid Baiturrahman. Secara umum, permasalahan fisik masjid adalah pencahayaan buatan yang kondisinya kurang layak (Gambar 2), mulai dari ruang dalam masjid, serambi, hingga ruang luarnya. Berdasarkan hasil wawancara yang dilakukan, ada empat aspek yang saling mempengaruhi, yaitu aspek keindahan, aspek keamanan, penghematan energi, dan aspek kebutuhan pencahayaan untuk ibadah.

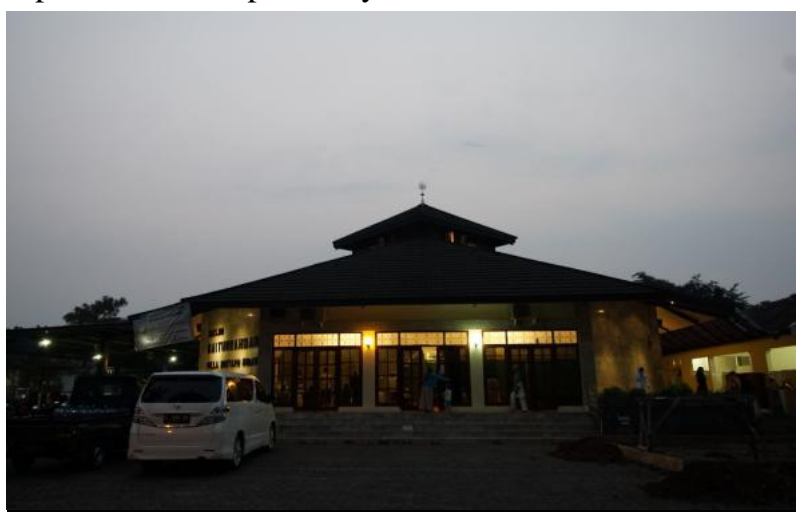

Gambar 2. Existing Masjid pada malam hari

Manusia memiliki hubungan erat dengan cahaya untuk mendukung aktivitas dan memberikan informasi visual. Kekurangan atau kelebihan cahaya berpengaruh pada kesehatan, keamanan, keselamatan, serta psikologi dan fisiologi manusia. Di sisi lain, lingkungan sekitar juga akan menerima dampak positif dari cahaya. Cahaya alami akan memberikan keuntungan pada lingkungan karena dapat mengurangi penggunaan energi listrik hasil pembakaran fosil, sementara cahaya buatan yang masih mengandalkan energi fosil akan mencemari lingkungan (Parmonangan, 2017).

Permasalahan yang timbul terhadap penggunaan cahaya untuk permukaan dan menara masjid ialah terjadinya pembengkakan tagihan listrik. Hal itu terjadi karena intensitas penggunaan lampu yang tinggi untuk permukaan dan menara masjid. Pencahayaan buatan yang baik pada malam hari akan membuat permukaan dan menara masjid tidak akan terlihat suram dan gelap, serta dapat mengurangi risiko terjadinya tindak kejahatan. Namun demikian, tanpa perencanaan teknis yang baik, seperti penggunaan jenis lampu, color 
temperature, dan color rendering yang tepat, tata cahaya ideal untuk keamanan tidak akan tercapai. Masalah keamanan inilah yang menjadi salah satu perhatian yayasan masjid agar dapat mencegah kejadian pencurian sepeda motor seperti yang telah terjadi sebelumnya.

Pada renovasi kali ini, permukaan bangunan mengalami perubahan yang cukup bermakna dari sebelumnya, sehingga pencahayaan buatan sangat diperlukan untuk menonjolkan karakter arsitektur pada desain masjid yang baru. Selain arsitek, desainer tata cahaya juga sangat berperan untuk menerjemahkan konsep arsitektur melalui tata cahaya buatan. Dari konsep tata cahaya tersebut, yang menjadi perhatian ialah penggunaan listrik yang mampu menyebabkan tagihan sangat besar dan cara perawatannya. Di Masjid Baiturrahman belum ada perencanaan khusus mengenai pencahayaan buatan dengan segala permasalahannya.

Analisis situasi dan permasalahan mitra di atas menggambarkan bahwa diperlukan solusi dalam mengatasi masalah keamanan di kompleks masjid. Tim pengabdi melakukan perencanaan dengan pendekatan teknis yang terukur menggunakan teknik pencahayaan fungsional dan kalkulasi pencahayaan dengan perangkat lunak DiaLux untuk pengukuran kuantitatif (Dial, 2018). Perangkat ini mampu menghitung kebutuhan lux suatu ruang sekaligus mengilustrasikan kondisi tata cahaya serta tingkat iluminasi yang sesuai dengan kebutuhan.

Ruang utama salat menjadi pertimbangan penting dalam menentukan kualitas pencahayaan agar tercipta suasana ruangan yang lebih nyaman untuk beribadah. Kuantitas pencahayaan yang diukur dalam satuan Lux menjadi tidak dominan dalam menciptakan karakter ruang seperti ini, maka pendekatan yang tepat untuk dilakukan ialah memperhatikan distribusi pencahayaan, warna cahaya, dan rendering cahaya (Holmes dan David, 2014).

Desain tata cahaya buatan yang dihasilkan akan membentuk elemen-elemen arsitektural islami dengan pola geometris arabesque. Hal tersebut akan menambah unsur keindahan karena tata cahaya yang baru akan mempertegas konsep efisiensi energi dalam perencanaan dan implementasinya. Upaya dalam mewujudkan efisiensi energi dilakukan dengan penerapan teknik pencahayaan yang selektif, pemanfaatan teknologi optik pada luminaire, penggunaan sumber cahaya terbaru yang mempunyai lumonius efficacy yang tinggi, dan penggunaan lighting control system yang memudahkan dan adaptif (Sutanto, 2017).

\section{METODE}

Perancangan sebuah desain merupakan proses yang berkelanjutan dan membutuhkan kerja sama antara desainer dan pemberi tugas. Desain partisipatif merupakan salah bentuk metode dalam perancangan (Sanders, dkk, 2002) sehingga klien, dalam hal ini adalah warga, menjadi bagian penting dari suatu proses perancangan sehingga rasa memiliki warga muncul karena telah dilibatkan dalam proses pembangunan tersebut. Pelaksanaan kegiatan ini terdiri FGD, perancangan, dan sosialisasi hasil rancangan (Gambar 3).

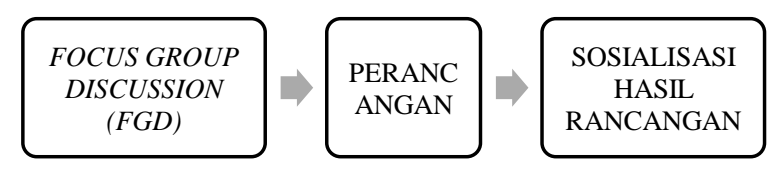

Gambar 3. Diagram alur metode

\subsection{Focus group discussion (FGD)}

FGD merupakan bagian dari proses perancangan yang melibatkan partisipasi aktif warga. Diskusi difokuskan pada permasalahan terkait tata cahaya dan dampaknya terhadap keindahan, keamanan, dan kualitas ibadah. Warga memberikan informasi dan data kepada tim pengabdi terkait kendala dalam hal tata cahaya buatan.

\subsection{Perancangan}

Pengabdian ini diawali dengan survei lokasi existing untuk mendapatkan data awal yang akan dianalisis untuk membuat konsep perancangan. Setelah mendapatkan konsep perancangan, tahap selanjutnya ialah membuat pengembangan desain lanjut. Pada tahap pengembangan desain lanjut, tim pengabdi menyiapkan presentasi awal yang terdiri dari gambar konsep desain dan pilihan luminaire yang akan digunakan. Tahap selanjutnya ialah melakukan kalkulasi pencahayaan untuk menguji apakah konsep awal perancangan sudah memenuhi standar kebutuhan pencahayaan. Setelah warga menyetujui konsep perancangan hingga rencana anggaran biaya, dilakukan tahap terakhir yaitu penyiapan dokumen konstruksi untuk keperluan tender dan pelaksanaan konstruksi (Gambar 4).

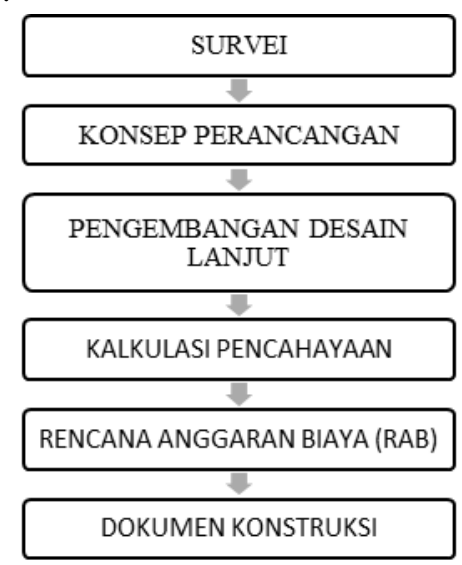

Gambar 4. Diagram alur perancangan 


\subsection{Sosialisasi hasil rancangan}

Sosialisasi hasil rancangan diawali dengan penataan ulang tata cahaya buatan yang lebih efisien dan berkualitas, lalu dilanjutkan FGD untuk menjaring informasi dan data dari warga. Sosialisasi selanjutnya merupakan bagian dari proses perancangan, yaitu menjelaskan konsep pencahayaan buatan kepada pengurus dan warga untuk mendapatkan umpan balik dari hasil perancangan. Tahap terakhir adalah presentasi hasil desain tata cahaya buatan kepada warga.

\section{HASIL DAN PEMBAHASAN}

\subsection{Inisiasi kegiatan dan focus group discussion}

Sesuai rencana kegiatan, komunikasi awal dengan Yayasan Masjid Baiturrahman dilakukan sejak bulan September 2018. Inisiasi kegiatan tersebut berfokus pada bentuk kegiatan, teknis pelaksanaan, dan keinginan tim pengabdian untuk melibatkan warga sebagai bentuk dari partisipati aktif masyarakat. Diskusi difokuskan pada permasalahan yang terkait langsung dengan tata cahaya dan dampaknya terhadap keindahan, keamanan, dan kualitas ibadah.

Proses inisiasi kegiatan dan FGD dengan mitra program tersebut dilaksanakan sebanyak 3 kali sepanjang September-November 2018 (Gambar 5). Pertemuan pertama dan kedua dilakukan dengan pengurus masjid, sedangkan pertemuan ketiga dilakukan bersama 20 warga. Hasil dari diskusi tersebut adalah warga setuju dan antusias terhadap peningkatan kenyamanan dalam hal penerangan untuk Masjid Baiturrahman dengan memaksimalkan pencahayaan buatan yang lebih baik di ruang dalam dan ruang luar. Hal ini didukung dengan biaya operasional energi listrik yang cukup memadai di masjid tersebut. Penggantian lampu dilakukan setiap enam bulan sekali dan saat menjelang Ramadhan. Hal tersebut dilakukan dengan harapan bahwa setelah dilakukan perancangan pencahayaan buatan pada area masjid penggunaan listrik dapat dihemat. Selain itu, masjid menjadi lebih terang, lebih indah, dan nyaman untuk beribadah. Pada akhir diskusi, warga mengusulkan dan menyepakati untuk menggunakan lampu yang berwarna kuning di bagian ruang dalam masjid agar suasana beribadah lebih tenang dan khidmat.

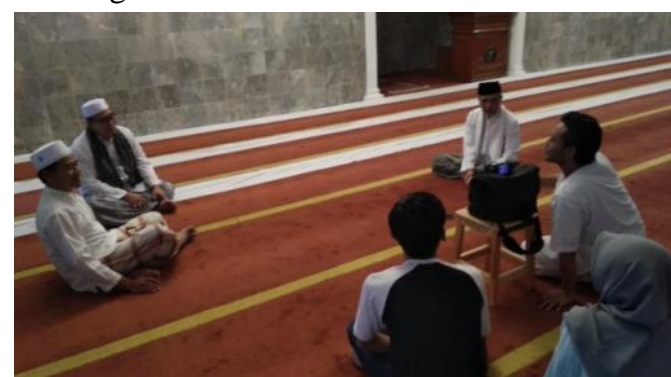

Gambar 5. Focus group discussion dengan pengurus masjid dan warga
Setelah tim pengabdi melakukan inisiasi kegiatan, tahap berikutnya adalah pengambilan data existing bangunan masjid dengan pengukuran mengacu pada data gambar awal yang dimiliki oleh pengurus Masjid Baiturrahman. Kegiatan pengukuran oleh tim pengabdi dapat dilihat pada Gambar 6.

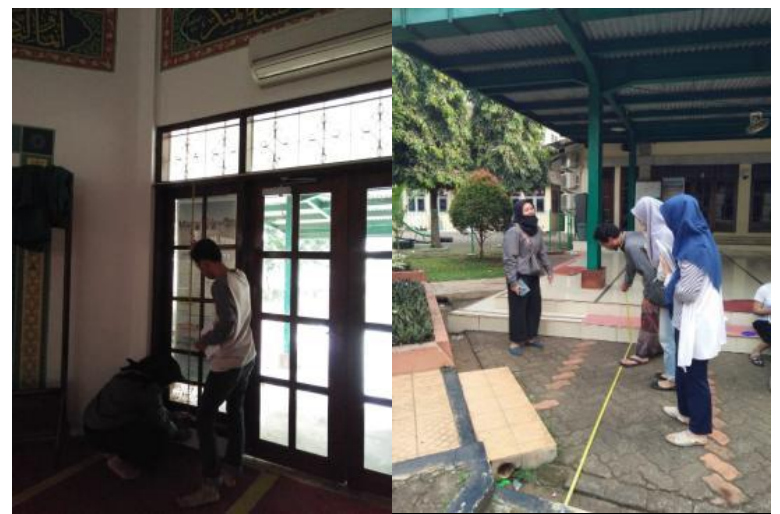

Gambar 6. Kegiatan pengukuran ruang dalam dan luar masjid

Pengukuran bangunan masjid dilakukan untuk mendata dimensi bangunan secara horizontal dan vertikal untuk memperoleh luasan yang digunakan sebagai data perhitungan beban cahaya yang dibutuhkan. Pengukuran dimulai dari ruang ibadah utama, teras, menara, tempat wudu, hingga area taman (Gambar 6). Setelah tim pengabdi melakukan pengukuran dan pendataan maka data yang diperoleh dianalisis. Tim pengabdi membagi pekerjaan berdasarkan spesifikasi keahlian anggota, yaitu perancangan titik lampu dan simulasi pencahayaan, penggambaran teknis, dan visualisasi gambar tiga dimensi. Koordinasi dilakukan secara berkala sesuai dengan timeline yang telah disepakati di awal pelaksanaan.

Masjid Baiturrahman memiliki dimensi utama bangunan 16,8 meter $\times 17,2$ meter (Gambar 7). Masjid ini memiliki teras yang mengelilingi tiga sisinya. Ruang salat luas dan menggunakan lampu gantung sebagai penerangan utama. Kondisi pencahayaan buatan pada ruang salat utama dan mihrab masih menggunakan sumber cahaya (lampu) dengan teknologi lama (incandescent lamp) yang jumlahnya 84 buah. Dengan penggunaan lampu tersebut maka efisiensi energi dan kuantitas pencahayaan menjadi berkurang. Tim pengabdi kemudian mengusulkan penggunaan sumber cahaya baru yang lebih efisien secara energi dan dipadukan dengan control system yang terintegrasi dengan fitting sehingga mampu mewujudkan rancangan pencahayaan buatan yang efisien dan efektif dengan kuantitas dan kualitas yang dapat dikontrol dengan mudah. 


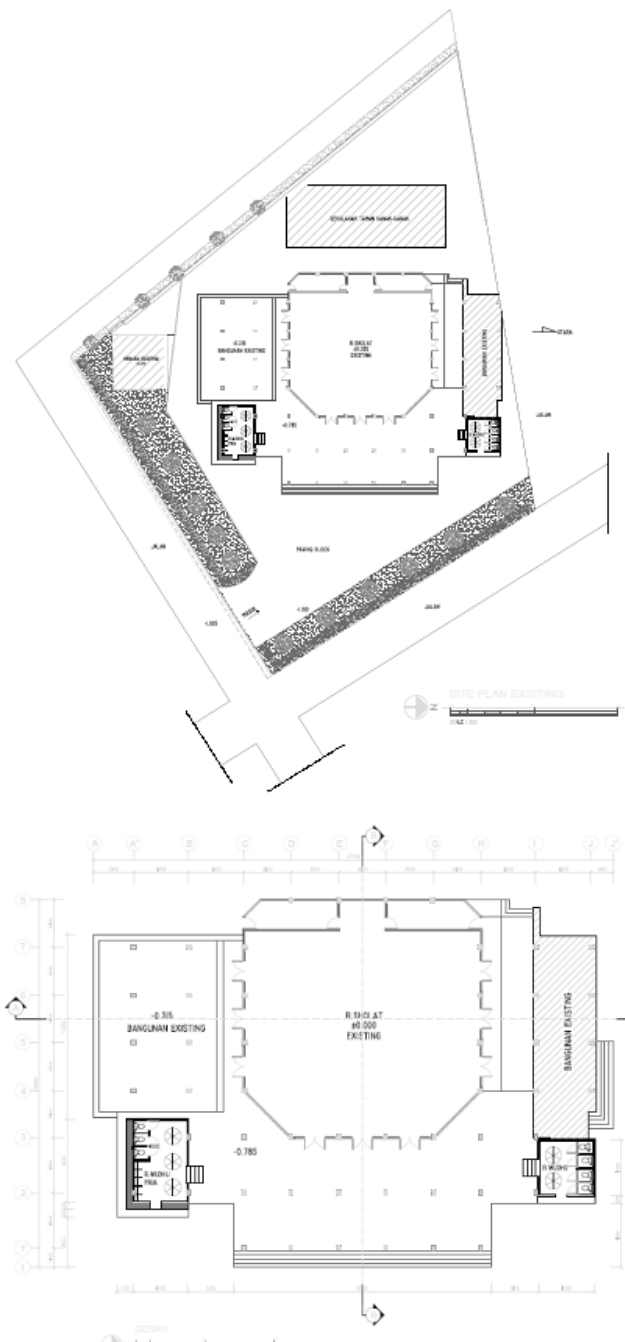

Gambar 7. Site plandan denah eksisting Masjid Baiturrahman

\subsection{Perancangan konsep pencahayaan pada masjid}

Setelah melakukan pengukuran, pendataan awal dari wawancara dan gambar yang dimiliki oleh DKM, tim pengabdi menganalisis data sebagai dasar pembuatan konsep perancangan pencahayaan buatan. Konsep pencahayaan Masjid Baiturrahman adalah konsep senja dengan mengimplementasikan spektrum warna gradasi warna biru ke oranye. Konsep ini dirancang pada area eksterior maupun interior bangunan.

\subsubsection{Eksterior (fasade, minaret, landscape)}

Konsep pencahayaan eksterior meghasilkan pencahayaan yang dapat memberi kesan aman, efisien, dan penanda jika ada momen perayaan. Landscape dan hardscape (Gambar 8) dirancang dengan warna putih, Fasade (Gambar 9) dirancang dengan ornamen Islam dan dilengkapi dengan pencahayaan warna hangat (4000 K) untuk menimbulkan kesan elegan. Berbeda dengan menara (Gambar 10) yang digunakan untuk penanda waktu atau kegiatan yang disesuaikan dengan waktu; saat malam Jumat digunakan warna statis (warna hangat atau putih $3000-5000 \mathrm{~K}$ ), dan saat peringatan hari raya Islam menggunakan warna yang lebih dinamis.

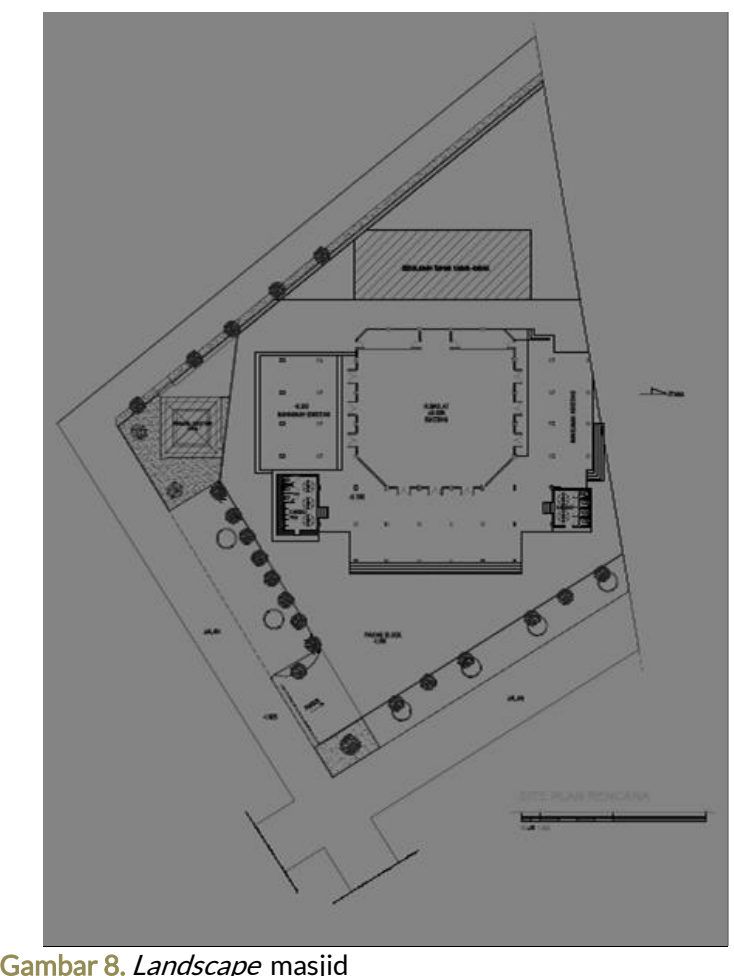

Gambar 8. Landscape masjid

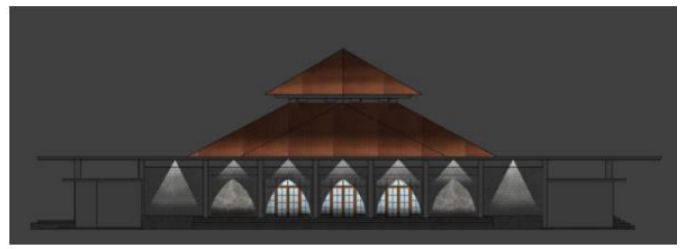

(a)

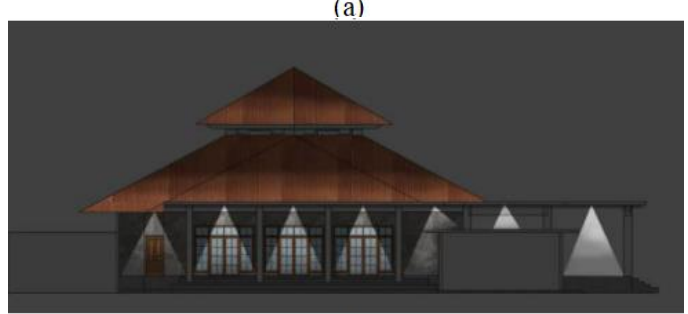

(b)

Gambar 9. (a) Fasade depan dan (b) fasade samping

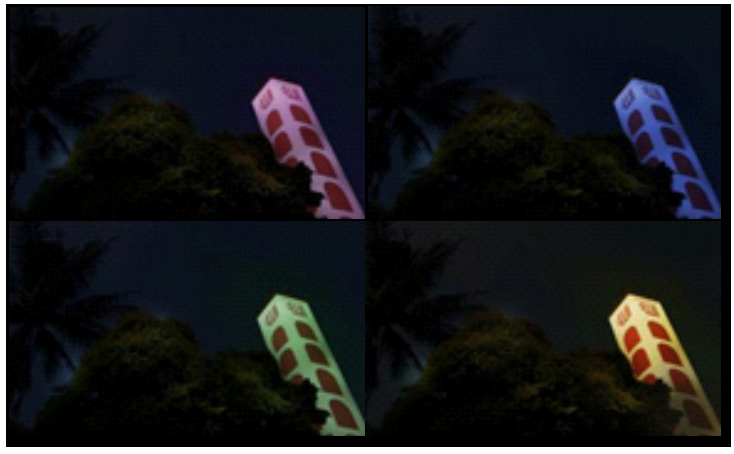

Gambar 10. Variasi pencahayaan minaret

\subsubsection{Interior (ruang ibadah utama dan mihrab, teras, tempat wudhu, dan ruang transisi)}

Rancangan pencahayaan buatan pada ruang ibadah utama dan mihrab menggunakan dua skema, yaitu skema saat jemaah sedang menunggu salat dimulai dan saat salat berjemaah berlangsung (Gambar 11). Saat menunggu salat berjemaah dimulai, maka pencahayaan 
di mihrab dimatikan, sedangkan pencahayaan akan menyebar dengan warna hangat $(3000 \mathrm{~K})$ di ruang salat, dan lux level di permukaan lantai sebesar 50 lux. Saat salat dimulai maka pencahayaan di mihrab dirancang dengan menggunakan teknik wall washing, dengan warna hangat $2700 \mathrm{~K}$, lux level di permukaan dinding sebesar 100 lux, sedangkan di ruang salat level diturunkan menjadi 20 lux. Berbeda dengan ruang salat, tempat wudu dan ruang transisi dirancang dengan menggunakan warna putih $500 \mathrm{~K}$ untuk alasan keamanan, dengan kuantitas lux level yang cukup tinggi yaitu 300 lux. Hal ini menjadi pertimbangan dalam kecukupan kapasitas penerangan saat jemaah melakukan sirkulasi wudu, transisi, dan tempat salat.

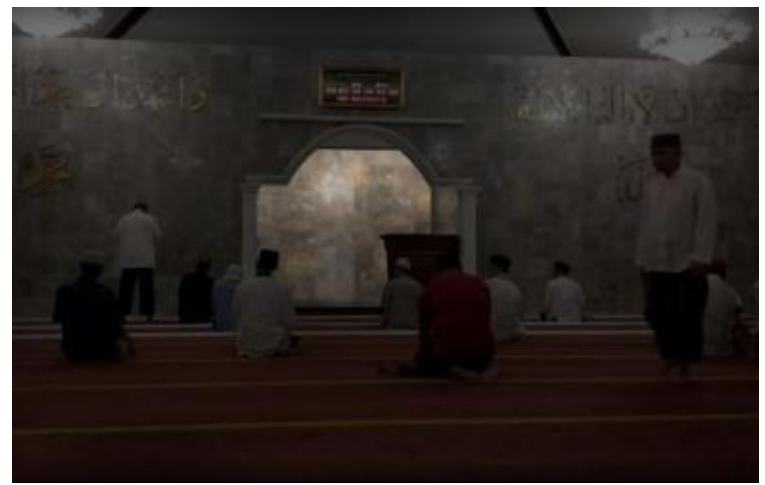

Gambar 11. Suasana mihrab dan ruang salat saat menunggu waktu salat

\subsection{Presentasi konsep pencahayaan kepada warga}

Setelah menyelesaikan perancangan pencahayaan buatan dengan menggunakan software DiaLux, tim pengabdi melakukan presentasi kepada jemaah setelah salat Shubuh selesai. Masukan dari para jemaah salah satunya adalah menambahkan referensi objek masjid dengan pencahaaan yang baik dari dalam negeri. Warga juga mengusulkan agar saat tim pengabdi membeli fixture lampu sebaiknya membeli yang mudah didapatkan sehingga memudahkan proses penggantian jika terjadi kerusakan. Tahap terakhir dari sosialisasi tersebut ialah mempresentasikan hasil akhir desain tata cahaya buatan kepada jemaah.

\subsection{Lighting design development}

Pada tahap pengembangan desain lanjut, tim pengabdi menyiapkan presentasi awal yang terdiri dari gambar konsep desain dan pilihan luminaire yang akan digunakan. Tahap selanjutnya adalah melakukan kalkulasi pencahayaan untuk menguji apakah konsep awal perancangan sudah memenuhi standar kebutuhan pencahayaan. Setelah warga menyetujui konsep perancangan hingga rencana anggaran biaya, maka tahap terakhir dari proses tersebut adalah menyiapkan dokumen konstruksi untuk keperluan tender dan pelaksanaan konstruksi.

Presentasi desain dilakukan dengan konten simulasi tata cahaya dengan perangkat lunak DiaLux, produksi visualisasi gambar 3 dimensi, dan perhitungan penggunaan energi. Tim pengabdi menghasilkan luaran berupa gambar kerja penitikan lampu (Gambar 12), kalkulasi pencahayaan (Gambar 13), control schedule, dan rencana anggaran biaya (Lampiran 1 dan Lampiran 2).

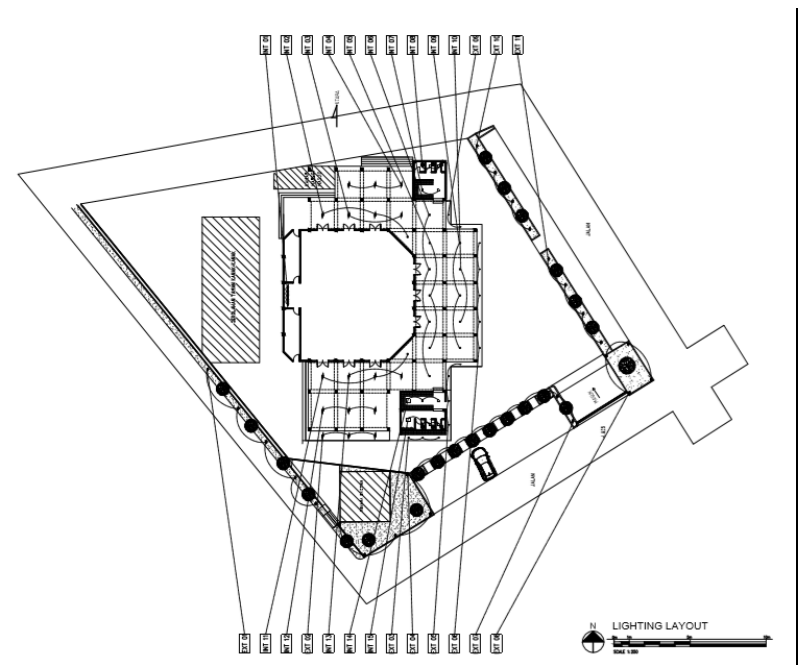

Gambar 12. Gambar kerja penitikan lampu

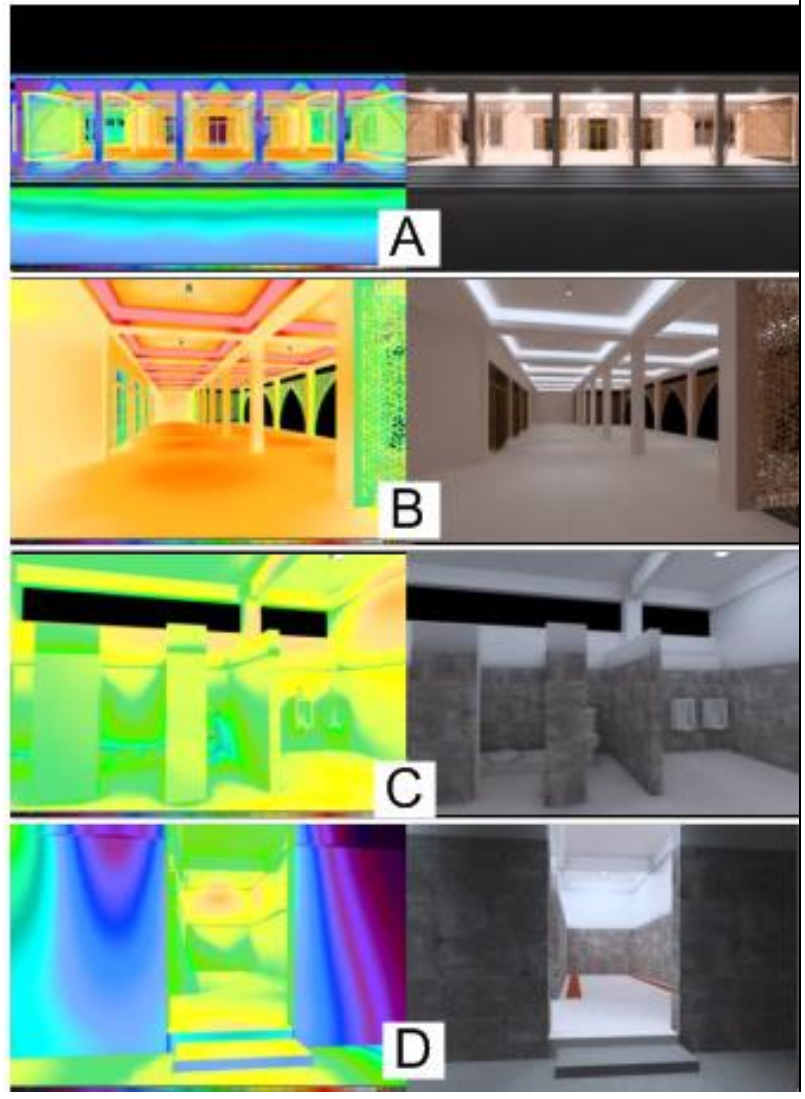

Gambar 13. Kalkulasi pencahayaan pada (a) fasade bangunan, (b) serambi masjid, (c) area toilet, dan (d) area wudhu

\subsection{Implementasi rancangan}

Implementasi ini dimulai dengan pemesanan lampu kepada pihak supplier untuk tender pengadaan lampulampu yang direncanakan. Setelah mendapatkan penawaran, tim pengabdi melakukan pembelian lalu merencanakan proses instalasi lampu pada masjid. Sebelum melakukan pemasangan, tim pengabdi dan tim elektrikal dari pengurus masjid melalukan pegecekan kesiapan instalasi dan lokasi titik-titik perencanaan 
lampu. Terakhir, pihak pengurus masjid menetapkan bagian serambi masjid yang menjadi prioritas pemasangan lampu pada tahap pertama. Untuk tahap pemasangan berikutnya dilakukan bersamaan dengan proses konstruksi selama satu tahun.

\subsection{Presentasi akhir, serah terima, dan umpan balik dari warga}

Setelah implementasi rancangan selesai, tim pengabdi melakukan presentasi akhir rancangan kepada pengurus masjid sekaligus melakukan serah terima hasil kegiatan pengabdian kepada masyarakat. Produk yang dipresentasikan sesuai dengan luaran yang direncanakan pada kegiatan pengabdian, yaitu gambar kerja 2D, gambar kerja penitikan lampu, kalkulasi pencahayaan, control schedule, dan rencana anggaran biaya (Gambar 12, Gambar 13, Lampiran 1, Lampiran 2).

Tahap akhir yang dilakukan adalah wawancara kepada pengurus masjid dan jemaah untuk mendapatkan umpan balik mengenai kegiatan yang telah dilakukan. Hasil dari wawancara tersebut membuktikan bahwa jemaah merasakan perbedaan suasana antara sebelum pencahayaan dirancang dan sesudahnya. Suasana masjid menjadi lebih baik, terang namun tidak menyilaukan mata, ruangan terkesan lebih luas sehingga suasana menjadi khidmat saat jemaah salat. Dengan adanya lampu indirect lighting (lampu yang tersembunyi) pada area serambi juga menambah kekhusyukan. Warna lampu yang kekuningan dengan tingkat luminasi yang sesuai menyebabkan energi panas yang dihasilkan oleh tiap lampu menambah kenyamanan dalam beribadah. Selain itu, pengurus masjid mengharapkan implementasi lampu yang dilakukan telah mempertimbangkan keberlanjutan penggunaan energi yang hemat sehingga dapat menekan biaya operasional dalam jangka panjang. Pengurus masjid juga berharap bahwa penggunaan lampu nantinya menyesuaikan dengan kebutuhan kegiatan yang berlangsung di dalam dan di luar masjid, seperti waktu ibadah salat yang lebih menggunakan sedikit pencahayaan dibandingkan dengan saat imam/ khatib melakukan ceramah dalam ruang ibadah utama. Hal ini telah diakomodir dalam rancangan yang dibuat oleh tim pengabdi.

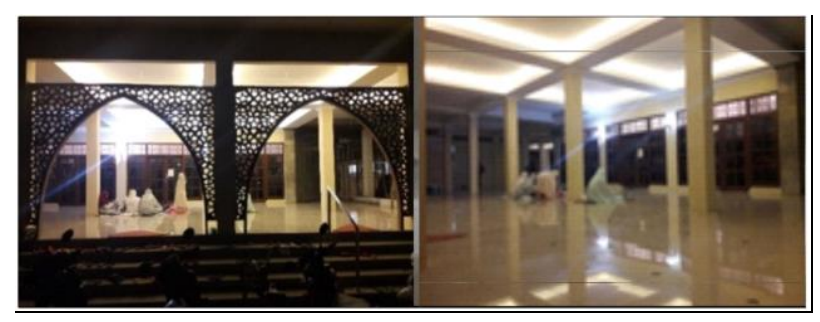

Gambar 11. Suasana masjid setelah rancangan diimplementasikan

\section{KESIMPULAN}

Efisiensi energi dan pencahayaan kualitatif merupakan kata kunci dari konsep besar perancangan tata cahaya buatan untuk Masjid Baiturrahman. Tata cahaya buatan memberikan rasa aman pada jemaah masjid ketika mereka memarkirkan kendaraan atau ketika mereka mengambil air wudu. Selain itu, tata cahaya dapat memberikan kenyamanan visual pada ruang utama salat sehingga menambah kenyamanan dalam beribadah. Pada aspek lain, tata cahaya dapat menonjolkan keindahan arsitektur masjid sehingga masyarakat lebih tertarik untuk datang ke masjid. Dengan luaran berupa konsep perancangan hingga rencana anggaran biaya, tim pengabdi mampu memberikan solusi penghematan energi, peningkatan kualitas ibadah, keamanan, dan keindahan Masjid Baiturrahman. Tim pengabdi menyarankan bahwa pencahayaan dalam arsitektur sebaiknya direncanakan bersamaan dengan proses desain arsitektur, bukan setelahnya atau bersamaan dengan proses konstruksi karena pencahayaan buatan merupakan bagian dari arsitektur dan bukan sesuatu yang ditambahkan pada akhir proses desain.

\section{UCAPAN TERIMA KASIH}

Ucapan terima kasih kami sampaikan kepada Lembaga Penelitian dan Pengabdian Masyarakat (LP2M), Universitas Pembangunan Jaya atas hibah internal yang diberikan melalui skema Hibah Pengabdian kepada Masyarakat tahun 2018.

\section{REFERENSI}

Dial. (2018, 31 Juli). DIALux Evo Manual: A collection of All Wiki Articles. Diakses darihttps://www.dial.de/fileadmin/documents/di alux/DIALux_downloads/DIALux \%20evo\%20 manual.pdf

Erco. (2018, 31 Juli). ERCO Guide. Diakses dari https://www.erco.com/download/content/3media/guide_pdf/00-komplett/erco-guide-en.pdf

Hofmann, H. \& Ganslandt, R. (1992). Handbook of Lighting Design. Lüdenscheid: Vieweg.

Holmes, David. (2014). Lighting Guide 13: Lighting for Places of Worship. London: The society of Light and Lighting.

Parmonangan, M. (2017). Cahaya dan Arsitektur. Yogyakarta: Teknosain.

Quran. (2019, 4 April). Surat An-Nuur Ayat 36. Diakses dari https://tafsirweb.com/6164-quran-surat-annur-ayat-36.html

Dirjen BIMAS. (2014). Keputusan Direktur Jendral Bimbingan Masyarakat Islam Nomor DJ.II/802 Tahun 2014 tentang Standar Pembinaan Manajemen Masjid.

Sanders, Elizabeth B-N; SonicRim. (2002). From UserCentered to Partisipatory Design Approach. 
Dalam J. Frascara, Design and Social Sciences: Making Connections. London And New York: Taylor and Francis.

Sutanto, E. B. H., 2017. Prinsip-Prinsip Perancangan Pencahayaan Buatan dalam Arsitektur. Yogyakarta: PT Kanisius.

Tamimi, A. 2018. Sejarah dan Perkembangan Masjid Baiturrahman. Hasil wawancara: Ketua Yayasan Masjid Baiturrahman. pada 8 September 2018.

Zumtobel. (2018, 31 Juli). The Lighting Handbook. Edisi 6: Diakses dari https://www.zumtobel.com/PDB/teaser/EN/licht handbuch.pdf. 


\section{CONTROL SCHEDULE}

\begin{tabular}{|c|c|c|}
\hline Broject: & Mastid Baiturrahman Vifla Bintrao Indah & Issue Date: 20 Juni 23019 \\
\hline Location & Jombang. Ciputat, Tangerang Selatan & Revision Date - - \\
\hline
\end{tabular}

\section{INTERIOR RUANG SHOLAT TERAS}

\begin{tabular}{|c|c|c|c|c|c|c|c|}
\hline $\begin{array}{c}\text { Control } \\
\text { Reference }\end{array}$ & $\begin{array}{l}\text { Light Fitting } \\
\text { Type }\end{array}$ & Quantity & $\begin{array}{c}\text { Lamp } \\
\text { Wattage }\end{array}$ & Lamp Type & $\begin{array}{l}\text { Circuit } \\
\text { Load }\end{array}$ & Circuit Type & Remarks \\
\hline INTO2 & RO 501 & 5 & 5 & LED & 30 & Switched & $220 \mathrm{~V}$ \\
\hline INT 03 & SD 301 & 2 & 5 & LED & 20 & Switched & $220 \mathrm{~V}$ \\
\hline INT 04 & SD 301 & 3 & $\mathrm{~s}$ & LED & 20 & Switched & $220 \mathrm{~V}$ \\
\hline INT 05 & SD 301 & 3 & 5 & LED & 20 & Switched & $220 \mathrm{~V}$ \\
\hline INT OB & SD 301 & 4 & s & LED & 30 & Switched & $220 \mathrm{~V}$ \\
\hline INT 09 & SD 301 & 3 & 5 & LED & 20 & Switched & $220 \mathrm{~V}$ \\
\hline INT 10 & SD 301 & 2 & 5 & LED & 20 & Switched & $220 \mathrm{~V}$ \\
\hline INT 11 & SD 301 & 3 & 5 & LED & 20 & Switched & $220 \mathrm{~V}$ \\
\hline INT 12 & SD 301 & 3 & 5 & LED & 20 & Switched & $220 \mathrm{~V}$ \\
\hline INV 01 & $L 100$ & 30 & 8 & LED & 220 & Switched & SEPARATE POWER SUPPLY \\
\hline INV 02 & L 100 & 30 & B & LED & 220 & Switched & SEPARATE POWER SUPPLY \\
\hline INV 03 & $L 100$ & 30 & B & LED & 220 & Switched & SEPARATE POWER SUPPLY \\
\hline ivv 04 & L 100 & 30 & 6 & LED & 220 & Switched & SEPARATE POWER SUPPLY \\
\hline INV 05 & L 100 & 35 & B & LED & 260 & Switched & SEPARATE POWER SUPPLY \\
\hline INV 06 & $L 100$ & 35 & B & LED & 260 & Switched & SEPARATE POWER SUPPLY \\
\hline NNV 07 & L 100 & 35 & 8 & LED & 260 & Swilched & SEPARATE POWER SUPPLY \\
\hline INV De & L 100 & 35 & B & LED & 260 & Switched & SEPARATE POWER SUPPLY \\
\hline INV 09 & $L 100$ & 35 & 6 & LED & 260 & Switched & SEPARATE POWER SUPPLY \\
\hline INV 10 & $L 100$ & 30 & B & LED & 220 & Switched & SEPARATE POWER SUPPLY \\
\hline INV 11 & $L 100$ & 30 & 8 & LED & 220 & Switched & SEPARATE POWER SUPPLY \\
\hline INV 12 & $L 100$ & 30 & 8 & LED & 220 & Switched & SEPARATE POWER SUPPLY \\
\hline INV 13 & $L 100$ & 30 & 8 & LED & 220 & Swilched & SEPARATE POWER SUPPLY \\
\hline INV 14 & $L 100$ & 30 & 6 & LED & 220 & Swilched & SEPARATE POWER SUPPLY \\
\hline
\end{tabular}

INTERIOR RUANG SHOLAT UTAMA

\begin{tabular}{|c|c|c|c|c|c|c|c|}
\hline $\begin{array}{c}\text { Control } \\
\text { Reference }\end{array}$ & $\begin{array}{l}\text { Light Fitting } \\
\text { Type }\end{array}$ & Quantity & $\begin{array}{c}\text { Lamp } \\
\text { Wattage }\end{array}$ & Lamp Type & $\begin{array}{l}\text { Circuit } \\
\text { Load }\end{array}$ & Circuit Type & Remarks \\
\hline INT 01 & RO 501 & 5 & 4 & LED & 30 & Local Dimmer & SEPARATE POWER SUPPLY \\
\hline INC O 1 & RT 100 & 9 & 4 & LED & 50 & $1-10 \mathrm{~V}$ & SEPARATE POWER SUPPLY \\
\hline INC 02 & RT 100 & 9 & 4 & LED & so & $1-10 \mathrm{~V}$ & SEPARATE POWER SUPPLY \\
\hline INC D3 & RT 100 & 8 & 4 & LED & 40 & $1-10 \mathrm{~V}$ & SEPARATE POWER SUPPLY \\
\hline INC OA & SD 301 & 8 & 4 & LED & 40 & $1-10 \mathrm{~V}$ & SEPARATE POWER SUPPLY \\
\hline INC D5 & RT 100 & 9 & 4 & LED & 50 & $1-10 \mathrm{~V}$ & SEPARATE POWER SUPPLY \\
\hline INC DE & RI 100 & 9 & 4 & LED & 50 & $1-10 \mathrm{~V}$ & SEPARATE POWER SUPPLY \\
\hline INC 07 & RT 100 & 8 & 4 & LED & 40 & $1-10 \mathrm{~V}$ & SEPARATE POWER SUPPLY \\
\hline INC OS & RT 100 & 8 & 4 & LED & 40 & $1-10 \mathrm{~V}$ & SEPARATE POWER SUPPLY \\
\hline INC 09 & RT 100 & 9 & 4 & LED & 50 & $1-10 \mathrm{~V}$ & SEPARATE POWER SUPPLY \\
\hline INC 10 & RT 100 & 9 & 4 & LED & so & $1-10 \mathrm{~V}$ & SEPARATE POWER SUPPLY \\
\hline INC 11 & RT 100 & 8 & 4 & LED & 40 & $1-10 \mathrm{~V}$ & SEPARATE POWER SUPPLY \\
\hline INC 12 & RT 100 & 8 & 4 & LED & 40 & $1-10 \mathrm{~V}$ & SEPARATE POWER SUPPLY \\
\hline INC 13 & RT 100 & 9 & 4 & LED & 50 & $1-10 \mathrm{~V}$ & SEPARATE POWER SUPPLY \\
\hline INC 14 & RT 100 & 9 & 4 & LED & 50 & $1-10 \mathrm{~V}$ & SEPARATE POWER SUPPLY \\
\hline INC 15 & RT 100 & 8 & 4 & LED & 40 & $1-10 \mathrm{~V}$ & SEPARATE POWER SUPPLY \\
\hline INC 16 & RT 100 & 8 & 4 & LED & 40 & $1-10 \mathrm{~V}$ & SEPARATE POWER SUPPLY \\
\hline
\end{tabular}

INTERIOR RUANG WUDHU

\begin{tabular}{|c|c|c|c|c|c|c|c|}
\hline $\begin{array}{c}\text { Control } \\
\text { Reforence }\end{array}$ & $\begin{array}{l}\text { Light Fitting } \\
\text { Type }\end{array}$ & Quantity & $\begin{array}{l}\text { Lamp } \\
\text { Wattage }\end{array}$ & Lamp Type & $\begin{array}{l}\text { Circuit } \\
\text { Load }\end{array}$ & Circuit Type & Remarks \\
\hline INT 07 & SD 301 & 1 & 12 & LED & 20 & Swisched & $220 \mathrm{~V}$ \\
\hline INT $0 B$ & SD 302 & 3 & 6 & LED & 30 & Swllched & $220 \mathrm{~V}$ \\
\hline INT 14 & SD 303 & 2 & B & LED & 20 & Swiched & $220 \mathrm{~V}$ \\
\hline INT 15 & SD 302 & 8 & 6 & LED & 60 & Swilched & $220 \mathrm{~V}$ \\
\hline
\end{tabular}




\section{CONTROL SCHEDULE}

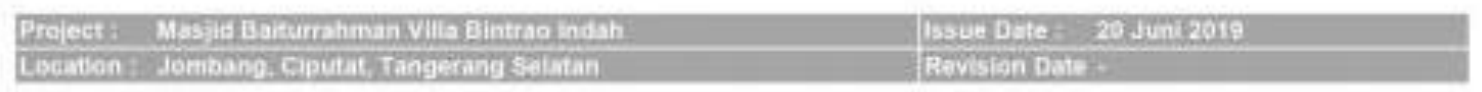

INTERIOR PENUNJANG

\begin{tabular}{|c|c|c|c|c|c|c|c|}
\hline $\begin{array}{c}\text { Contral } \\
\text { Reference }\end{array}$ & $\begin{array}{l}\text { Light Fitting } \\
\text { Type }\end{array}$ & Quantity & $\begin{array}{l}\text { Lamp } \\
\text { Wattaose }\end{array}$ & Lamp Type & $\begin{array}{l}\text { Circuat } \\
\text { Load }\end{array}$ & Cireuit Type & Remarks \\
\hline INT 16 & Di 100 & 2 & 8 & EED & 20 & Swoched & $200 \mathrm{~V}$ \\
\hline INT 17 & D 100 & 2 & 8 & LED & 20 & Swoched & $2200 \mathrm{~V}$ \\
\hline INT 18 & D. 100 & 2 & 8 & LED & 20 & Swleched & $2200 \mathrm{~V}$ \\
\hline INT 19 & D. 100 & 2 & 8 & LED & 20 & Switched & $200 \mathrm{~V}$ \\
\hline INT 20 & DC 100 & 4 & 8 & LED & 40 & Switched & $220 \mathrm{~V}$ \\
\hline
\end{tabular}

\section{EXTERIOR FACADE BANGUNAN}

\begin{tabular}{|c|c|c|c|c|c|c|c|}
\hline $\begin{array}{c}\text { Control } \\
\text { Reterence }\end{array}$ & $\begin{array}{l}\text { Light Fitting } \\
\text { Type }\end{array}$ & Quantify & $\begin{array}{c}\text { Lamp } \\
\text { Wattage }\end{array}$ & Lamp Type & $\begin{array}{l}\text { Circuint } \\
\text { Load }\end{array}$ & Cireuit Type & Remarks \\
\hline EXT 02 & DL 101 & 3 & 7 & LED & 30 & Sulbched & $220 \mathrm{~V}$ \\
\hline EXT 03 & DC 101 & 3 & 7 & LED & 30 & Sinteched & $220 \mathrm{~V}$ \\
\hline EXT 05 & D. 101 & 3 & 7 & LED & 30 & Swbched & $2200 \mathrm{~V}$ \\
\hline EXT 06 & DC 101 & 3 & 7 & LED & 30 & Swilched & $2200 \mathrm{~V}$ \\
\hline EXT 09 & C 101 & 3 & 7 & LED & 30 & Smbched & $2200 \mathrm{~V}$ \\
\hline EXT 14 & DC 101 & 9 & 7 & LED & 30 & Switched & $2200 \mathrm{~V}$ \\
\hline EXT 15 & D. 101 & 3 & 7 & LED & 30 & Switched & $200 \mathrm{~V}$ \\
\hline
\end{tabular}

\section{EXTERIOR FACGADE MENARA}

\begin{tabular}{|ccccccccc|}
\hline $\begin{array}{c}\text { Control } \\
\text { Reference }\end{array}$ & $\begin{array}{c}\text { Light Fitting } \\
\text { Type }\end{array}$ & Quantity & $\begin{array}{c}\text { Lamp } \\
\text { Wattage }\end{array}$ & Lamp Type & $\begin{array}{c}\text { Circuit } \\
\text { Load }\end{array}$ & Circuit Type & Remarks \\
\hline RGB 01 & DL 101 & 12 & 24 & LED & 350 & DMXControl & $220 \mathrm{~V}$ \\
\hline RGB 02 & DL 101 & 12 & 24 & LED & 350 & OMXControl & $220 \mathrm{~V}$ \\
\hline
\end{tabular}

\section{LANDSCAPE}

\begin{tabular}{|c|c|c|c|c|c|c|c|}
\hline $\begin{array}{c}\text { Control } \\
\text { Reference }\end{array}$ & $\begin{array}{l}\text { Lught Fitting } \\
\text { Type }\end{array}$ & Quantity & $\begin{array}{l}\text { Lamp } \\
\text { Wattace }\end{array}$ & Lamp Type & $\begin{array}{l}\text { Circuit } \\
\text { Load }\end{array}$ & Creuit Type & Remarks \\
\hline EXT01 & UP 100 & 5 & 11 & LED & 70 & Switched & $2200 \mathrm{~V}$ \\
\hline ExT a7 & UP 100 & 8 & 11 & LED & 110 & Switched & $220 \mathrm{~V}$ \\
\hline Ext as & UP 100 & 6 & 11 & LED & 90 & Swhoned & $2200 \mathrm{~V}$ \\
\hline EXT 10 & UP 100 & 5 & 11 & LED & 70 & Switched & $2200 \mathrm{~V}$ \\
\hline EXT 11 & UP 100 & 4 & 11 & LED & 60 & Bwitohed & $2200 \mathrm{~V}$ \\
\hline EXT 16 & DL 101 & 4 & 11 & LED & 60 & Switched & $220 \mathrm{~V}$ \\
\hline EXT17 & DC 101 & 2 & $\$ 4$ & LED & 130 & Swosched & $2200 \mathrm{~V}$ \\
\hline EXT 18 & DC 101 & 2 & 54 & LED & 130 & Swbehed & $220 \mathrm{~V}$ \\
\hline
\end{tabular}

6100 
Lampiran 2. Rencana anggaran biaya (RAB)

RENCANA ANGGARAN BIAYA

FITING LAMPU

MASJID BAITURRAHMAN, VILLA BINTARO INDAH

\begin{tabular}{|c|c|c|c|c|c|}
\hline \multirow{2}{*}{ NO } & \multirow{2}{*}{ JENIS PEKERJAAN } & \multirow{2}{*}{ VOL } & \multirow{2}{*}{ SAT } & \multicolumn{2}{|c|}{ HARGA } \\
\hline & & & & SATUAN & PEKERJAAN \\
\hline \multirow{6}{*}{1} & Fitting Lampu Area Ruang Sholat Utama & & & & \\
\hline & Downlight untuk Mihrab & 5 & $\mathrm{bh}$ & 475.000 & 2.375 .000 \\
\hline & \begin{tabular}{|l|} 
Dimmable Driver untuk Mihrab \\
\end{tabular} & 1 & $\mathrm{bh}$ & 450.000 & 450.000 \\
\hline & Lampu LED Retrofit Dimmable untuk Chandelie & 136 & $\mathrm{bh}$ & 270.000 & 36.720 .000 \\
\hline & \begin{tabular}{|l|l} 
Dimmable Driver untuk Chandelier & \\
\end{tabular} & 16 & $\mathrm{bh}$ & 750.000 & 12.000 .000 \\
\hline & & & & Total 1 & 51.545 .000 \\
\hline \multirow{5}{*}{2} & Fitting Lampu Area Ruang Sholat Teras Sisi Kiri & & & & \\
\hline & Recessed Downlight & 8 & $\mathrm{bh}$ & 290.000 & 2.320 .000 \\
\hline & \begin{tabular}{|l} 
Linear LED untuk Cove Lighting \\
\end{tabular} & 118 & $m^{\prime}$ & 92.000 & 10.856 .000 \\
\hline & Driver untuk Cove Lighting & 24 & $\mathrm{bh}$ & 145.000 & 3.480 .000 \\
\hline & & & & Total 2 & 16.656 .000 \\
\hline \multirow{5}{*}{3} & \multicolumn{2}{|l|}{ Fitting Lampu Area Ruang Sholat Teras Sisi Depan } & & & \\
\hline & \begin{tabular}{|l|} 
Surface Mounted Downlight \\
\end{tabular} & 12 & $\mathrm{bh}$ & 350.000 & 4.200 .000 \\
\hline & Linear LED untuk Cove Lighting & 170 & $\mathrm{~m}^{\prime}$ & 92.000 & 15.640 .000 \\
\hline & Driver untuk Cove Lighting & 34 & $\mathrm{bh}$ & 145.000 & 4.930 .000 \\
\hline & & & & Total 3 & 24.770 .000 \\
\hline \multirow{5}{*}{4} & \multicolumn{2}{|l|}{ Fitting Lampu Area Ruang Sholat Teras Sisi Kanan } & & & \\
\hline & \begin{tabular}{|l|} 
Surface Mounted Downlight \\
\end{tabular} & 8 & $\mathrm{bh}$ & 350.000 & 2.800 .000 \\
\hline & Linear LED untuk Cove Lighting & 112 & $\mathrm{~m}^{1}$ & 92.000 & 10.304 .000 \\
\hline & Driver untuk Cove Lighting & 23 & $\mathrm{bh}$ & 145.000 & 3.335 .000 \\
\hline & & & & Total 4 & 16.439 .000 \\
\hline \multirow{4}{*}{5} & Fitting Lampu Area Ruang Wudhu Pria & & & & \\
\hline & Surface Mounted IP Rated Fitting 8 Watt & 3 & $\mathrm{bh}$ & 220.000 & 660.000 \\
\hline & Surface Mounted IP Rated Fitting 6 Watt & 3 & $\mathrm{bh}$ & 185.000 & 555.000 \\
\hline & & & & Total 5 & 1.215 .000 \\
\hline \multirow{4}{*}{6} & Fitting Lampu Area Ruang Wudhu Wanita & & & & \\
\hline & Surface Mounted IP Rated Fitting 12 Watt & $1:$ & $\mathrm{bh}$ & 290.000 & 290.000 \\
\hline & Surface Mounted IP Rated Fitting 6 Watt & 3 & $\mathrm{bh}$ & 185.000 & 555.000 \\
\hline & & & & Total 6 & 845.000 \\
\hline \multirow{3}{*}{7} & Fifting Lampu Façade Bangunan & & & & \\
\hline & Directional Surface Mounted Downlight & 22 & $\mathrm{bh}$ & 550.000 & 12.100 .000 \\
\hline & & & & Total 7 & 12.100 .000 \\
\hline \multirow{5}{*}{8} & Fitting Lampu Façade Menara & & & & \\
\hline & Linear Wallwashing RGB & 24 & $\mathrm{bh}$ & 3.500 .000 & 84.000 .000 \\
\hline & Driver untuk Linear Wallwashing & 4 & $\mathrm{bh}$ & 800.000 & 3.200 .000 \\
\hline & DMX Control System \& Software & 1 & set & 4.000 .000 & 4.000 .000 \\
\hline & & & & Total 8 & 91.200 .000 \\
\hline \multirow{4}{*}{9} & Fitting Lampu Landscape & & & & \\
\hline & Uplight untuk Pohon & 32 & $\mathrm{bh}$ & 350.000 & 11.200 .000 \\
\hline & Pole Light untuk Area Parkir & 4 & $\mathrm{bh}$ & 5.500 .000 & 22.000 .000 \\
\hline & & & & Total 9 & 33.200 .000 \\
\hline \multirow{5}{*}{10} & Fitting Lampu Ruang Penunjang & & & & \\
\hline & Downlight Kamar Imam dan Merbot Masjid & 4 & $b h$ & 175.000 & 700.000 \\
\hline & Downlight Gudang dan Ruang Kontrol & 2 & $\mathrm{bh}$ & 175.000 & 350.000 \\
\hline & Downlight Ruang Kantor Yayasan & $4 \mid$ & $\mathrm{bh}$ & 175.000 & 700.000 \\
\hline & Total 10 & & & & 1.750 .000 \\
\hline
\end{tabular}

\section{TOIAL}

249.720 .000 